\title{
ACTH-Producing Pituitary Gland
}

\section{Carcinoma}

National Cancer Institute

\section{Source}

National Cancer Institute. ACTH-Producing Pituitary Gland Carcinoma. NCI Thesaurus.

Code C5964.

A rare, hormonally functioning or non-functioning pituitary gland adenocarcinoma that produces corticotropin. It may be associated with Cushing disease. 